\title{
Membrane Permeability as a Cause of Transport Defects in Experimental Fanconi Syndrome
}

\author{
A NEW HYPOTHESIS
}

\author{
M. Bergeron, L. Dubord, and C. Hausser, with the technical assistance \\ of C. SchwAB \\ From the Département de Physiologie, Université de Montréal, \\ Montréal, Québec
}

A в S T R A C T The injection of sodium maleate (200$400 \mathrm{mg} / \mathrm{kg}$ ) into rats produces aminoaciduria along with glycosuria and phosphaturia, resembling the Fanconi syndrome. This experimental model was studied by means of microinjections into proximal convoluted tubules of the kidney, stop-flow diuresis, and microperfusion of single nephrons. Our results show that, in maleate-treated rats, competition between amino acids of related structures (L-proline, L-OH-proline, and glycine) possesses the same characteristics, and net influx of amino acids appear normal at the proximal nephron. Data obtained by classical stop-flow techniques and single nephron microperfusions also indicate a normal entry of labeled amino acids (L-lysine, glycine, L-valine, L-proline, L-cystine), and 3-O-methyl-D- $\left[{ }^{3} \mathrm{H}\right]$ glucose and $\left[{ }^{32} \mathrm{P}\right]$ phosphate from the luminal side of the proximal tubule cell. However, the efflux of molecules from the cell appears enhanced throughout the proximal and distal tubule; molecules that exit at this site are excreted directly into the urine. Our results suggest that the phosphaturia, aminoaciduria, and glycosuria of the experimental Fanconi syndrome can be explained by a modification of the cell membrane permeability (increased efflux) at distal sites of the nephron rather than by a modification of the membrane transport (decreased influx) at the proximal sites, as is currently accepted. Our data also stress the importance of efflux phenomena in membrane transport.

This work was presented in part at the Annual Meeting of the Canadian Society for Clinical Investigation (Clin. Res. 21: 1036, 1973) and at the XXVIth International Congress of Physiological Sciences, New Delhi, 1974.

C. Hausser was the recipient of a summer medical student award from the Medical Research Council of Canada.

Received for publication 23 May 1975 and in revised form 22 December 1975.

\section{INTRODUCTION}

The Fanconi syndrome refers in general to a group of functional defects such as a generalized aminoaciduria, glycosuria, and phosphaturia (1). These urinary abnormalities are generally considered to result from "defective renal tubular reabsorption" (2). In fact, a morphological lesion of the proximal tubule was described and thought to cause this syndrome in cystinosis $(3,4)$. However, studies carried out with maleatetreated rats, a model of the Fanconi syndrome $(5,6)$, have indicated that the entry of amino acids into the renal cell appears to be normal in vitro and in vivo $(7,8)$. Another mechanism had to be sought to explain the phosphaturia, aminoaciduria, and glycosuria seen in experimental Fanconi syndrome.

Our results confirm that there is a normal net influx of amino acids and glucose into the proximal nephron and an increase in the permeability of the entire nephron, but indicate that the distal nephron involvement is the final cause of the urinary abnormalities seen in the experimental Fanconi syndrome.

\section{METHODS}

Materials. Uniformly labelled $\mathrm{L}-\left[{ }^{3} \mathrm{H}\right]$ proline $(45.7 \mathrm{Ci} /$ $\mathrm{mM}), \quad L-\left[4,5^{3} \mathrm{H}\right]$ lysine $(40 \mathrm{Ci} / \mathrm{mM}), \quad$ L- $\left[{ }^{14} \mathrm{C}\right]$ lysine $(260$ $\mathrm{mCi} / \mathrm{mM}), \mathrm{L}-\left[2,3-{ }^{3} \mathrm{H}\right]$ valine $(25 \mathrm{Ci} / \mathrm{mM}),\left[{ }^{14} \mathrm{C}\right]$ glycine $(78.7$ $\mathrm{mCi} / \mathrm{mM}), \quad\left[2{ }^{3} \mathrm{H}\right]$ glycine $(15 \mathrm{Ci} / \mathrm{mM}), \quad 3-O$-methyl-D$\left[\right.$ meth $\left.y /-{ }^{3} \mathrm{H}\right]$ glucose $\left.(4 \mathrm{Ci} / \mathrm{mM}), \quad[\text { carbox })^{\prime 14} \mathrm{C}\right]$ inulin $(2$ $\mathrm{mCi} / \mathrm{g}$ and $3 \mathrm{mCi} / \mathrm{g}$ ), and carrier-free $\left[{ }^{32} \mathrm{P}\right]$ phosphate were supplied by New England Nuclear, Boston, Mass. L- $\left.{ }^{35} \mathrm{~S}\right]-$ cystine $(3.46 \mathrm{Ci} / \mathrm{mM})$ was purchased from Schwarz/Mann Div., Becton, Dickinson \& Co., Orangeburg, N. Y. Reagent-grade unlabeled amino acids, purchased from Schwarz/ Mann, were used throughout.

Microinjection experiments. Experiments were performed on Sprague-Dawley female rats weighing about $200 \mathrm{~g}$, fed a standard laboratory diet. Animals were fasted $24 \mathrm{~h}$ before the experiment but had free access to tap water. 
Animals and solutions for injections were prepared according to a method previously described $(9,10)$.

The rats were anaesthetized with veterinary Nembutal (pentobarbital, Abbott Laboratories, North Chicago, Ill., 60 $\mathrm{mg} / \mathrm{kg}$ ) and placed on a heating table. A tracheotomy was performed and a fine polyethylene catheter (PE 10) was inserted into the jugular vein. D-mannitol, diluted to $5 \%$ in isotonic saline, was infused through the catheter by a constant perfusion pump at a rate equivalent to $5 \%$ of the body weight per hour. The left kidney was exposed by the technique of Gottschalk and Mylle (11): after a large Tlaparatomy, the viscera were reclined on the right side and covered by a moist gauze and a Parafilm sheet (Para Mfg. Co., Inc., Cranford, N. J.). A thermometer was placed in the viscera to maintain the temperature between 37 and $38^{\circ} \mathrm{C}$. Both ureters were catheterized. When the urinary flow was stable, the left kidney was covered with paraffin oil and microinjections were performed through the capsule under stereomicroscopic control with the aid of a de Fonbrune micromanipulator. A series of rats received an intraperitoneal injection of sodium maleate $(100 \mathrm{mg} / \mathrm{kg}), 2$ or $24 \mathrm{~h}$ before the beginning of the experiment. The maleate solution, made with maleic anhydride (Fisher Scientific Co., Pittsburgh, Pa.) dissolved in isotonic saline, was adjusted to $\mathrm{pH} 7.0-7.2$ with $5 \mathrm{~N} \mathrm{NaOH}$.

Radioactive solutions of L-amino acids were made in isotonic saline at the most convenient radioactivity and kept under oil in capillaries at $-20^{\circ} \mathrm{C}$. Labeled inulin and traces of lissamine green $(<1 \%)$ were added to these solutions. Unlabeled solutions of L-amino acids were also made in isotonic saline, adjusted to $\mathrm{pH} 7$, and kept at $0^{\circ} \mathrm{C}$ for periods not exceeding 2 wk to prevent bacterial lysis. The morning of the experiment, aliquots of labeled and unlabeled amino acids were placed under oil on a watch glass. Droplets of the labeled and the unlabeled solutions were then made with the aid of a calibrated pipette $(2.7,3.6$, or $7 \mathrm{pl}$ ): each radioactive droplet was mixed with a droplet of saline (control injection) or with a droplet of unlabeled amino acid, and the mixture was collected into a micropipette.

Up to four microinjections of similar duration were made at a given point in a proximal tubule. The presence of lissamine green and inulin permitted control of the quality of successive injections in the same tubule. Injections where less than $90 \%$ of the injected inulin was recovered in the urine were rejected.

Results are expressed as mean reabsorptions and calculated as follows: Mean reabsorption ( $\%$ of the injected quantity) $=\Sigma$ (\% reabsorption of the injected quantity) $N$ tubules. The reabsorption percentage of the injected quantity can be determined easily if the quantities injected and excreted are known: \% reabsorption of the injected quantity $=(\mathrm{dpm}$ injected $-\mathrm{dpm}$ excreted $/ \mathrm{dpm}$ injected $)$ $\times 100$.

Stop-flow technique. The stop-flow technique was performed by the technique of Malvin, et al. (12), as modified by Lambert, et al. (13). Male Sprague-Dawley albino rats, weighing 550-600 g, were anesthetized with Nembutal. A tracheotomy was performed and a polyethylene tube inserted into the jugular vein. A solution of $20 \%$ mannitol in $0.9 \% \mathrm{NaCl}$ was administered with a constant infusion pump at the rate of $0.4 \mathrm{ml} / \mathrm{min}$. Through a small abdominal incision, the bladder was pulled out with a hemostatic clamp and both ureters were cannulated. When the urinary flow was steady, one urinary catheter was clamped. 9 min later $0.2 \mathrm{ml}$ of a solution containing $100 \mu \mathrm{Ci}$ of ${ }^{22} \mathrm{PO}_{4}$ and $10 \mu \mathrm{Ci}$ of $\left[{ }^{3} \mathrm{H}\right]$ inulin was rapidly injected into the jugular vein.
3 min later, the clamp was released and urine was collected drop by drop for 10 min into vials containing a scintillating solution (Aquasol, New England Nuclear). These samples were thereafter analyzed for their ${ }^{3} \mathrm{H}$ and ${ }^{14} \mathrm{C}$ content (or ${ }^{35} \mathrm{~S}$, or ${ }^{32} \mathrm{P}$ ). Sodium maleate was injected intraperitoneally at a dosage of $100-400 \mathrm{mg} / \mathrm{kg}$. Only rats showing a glycosuria and a $\mathrm{pH}$ elevation were used. Other labeled molecules were used, such as $3-O-$ methyl-D- $\left[{ }^{3} \mathrm{H}\right]$ glucose, $\mathrm{L}-\left[{ }^{14} \mathrm{C}\right]-$ lysine, $\left[{ }^{14} \mathrm{C}\right]$ glycine, $\mathrm{L}-\left[{ }^{14} \mathrm{C}\right]$ proline, $\mathrm{L}-\left[{ }^{16} \mathrm{C}\right]$ valine, or $\mathrm{L}-\left[{ }^{36} \mathrm{~S}\right]-$ cystine.

Stop-flow microperfusion of single tubules. A second series of experiments was made with microperfusion of single tubules; experiments were performed on SpragueDawley female rats weighing about $200 \mathrm{~g}$. Animals and solutions of injections were prepared as described above. One nephron was injected first by oil, followed by a column of liquid containing radioactive inulin and amino acid or glucose and sealed by oil (Fig. 1). Inulin was used to check the quality of the injection and the quality of the oil block. As inulin is not reabsorbed, any urinary sample showing the presence of radioactive inulin was rejected. One stop-flow was made in a normal rat as a control and a second stopflow performed after the rat had been rendered glycosuric by an injection of sodium maleate (as above). A neutral

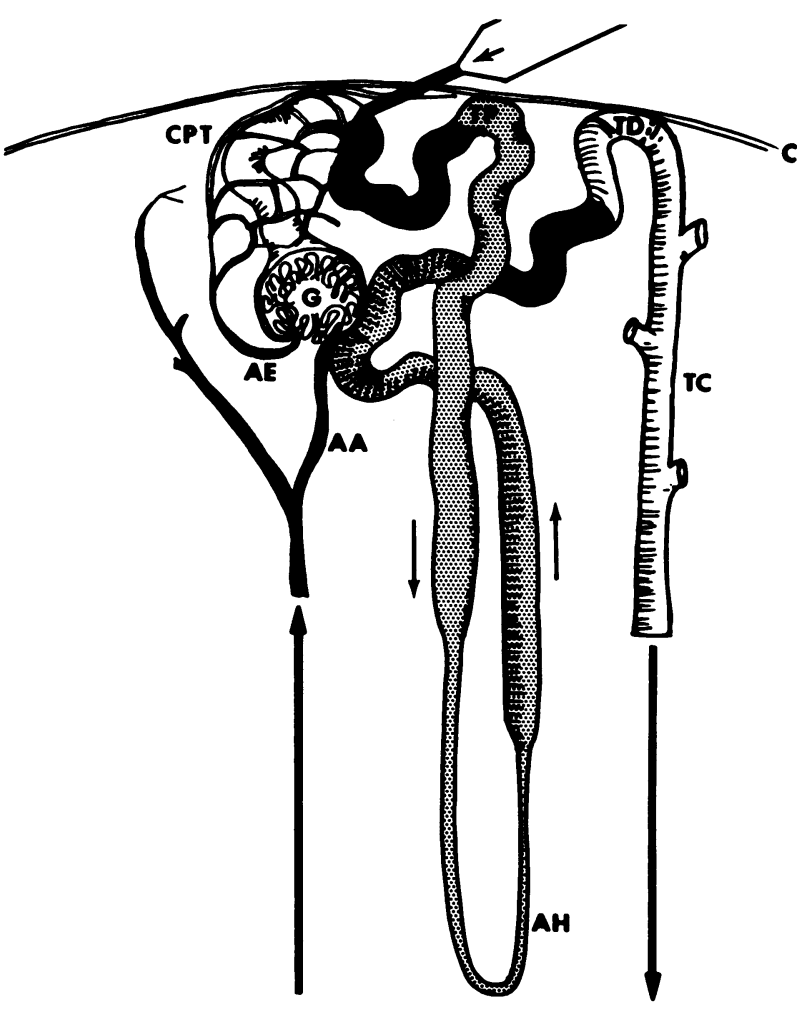

FIGURE 1 Schematic representation of a superficial nephron, illustrating the stop-flow microperfusion of a single tubule. A solution of labeled inulin and of a labeled amino acid or sugar remains stationary between two oil droplets. Aspiration of the newly formed glomerular filtrate is made with the pipette at the site of injection. C, capsule; CPT, peritubular capillary; G, glomerulus; AA, afferent arteriole; $\mathrm{AE}$, efferent arteriole; TP, proximal tubule; $\mathrm{AH}$, loop of Henle; TC, collecting tubule; TD, distal tubule. 
amino acid, $\mathrm{L}-\left[{ }^{3} \mathrm{H}\right]$ valine, and an unmetabolizable sugar, 3$O$-methyl-D- $\left[{ }^{3} \mathrm{H}\right]$ glucose, were studied. Fractionated urinary collections were made simultaneously from both ureters every $30 \mathrm{~s}$ for 15 or $20 \mathrm{~min}$.

\section{RESULTS}

Microinjection studies. The present results were obtained from 28 animals in which 259 microinjections were performed in 81 proximal tubules.

The absorption of imino acids and glycine has been previously studied in vivo at the luminal membrane of the rat nephron (10). Successive injections of similar duration and similar amino acid radioactivity were carried out at the same point of proximal convolutions; similar concentrations of unlabeled glycine, L-proline, or L-hydroxyproline were used as competitors of $\mathrm{L}-\left[{ }^{3} \mathrm{H}\right]$ proline absorption. Comparisons between these fractional reabsorptions were used as an index of the inhibition introduced by the competitor.

While in the absence of any competition (control) the average absorption in 15 tubules was $76 \% \pm 2.6$ of the injected quantity, an excess of unlabeled glycine slightly reduced this absorption to $69.4 \% \pm 3.2$, or $90.9 \%$ of the control (Fig. 2A). The absorption of $\mathrm{L}-\left[{ }^{3} \mathrm{H}\right]-$ proline was further depressed by the addition of L-proline $(33.3 \% \pm 5.2$ of the control) and L-hydroxyproline $(45.3 \% \pm 7.3$ of the control).

A series of microinjections was then made into rats having received an intraperitoneal injection of sodium maleate $24 \mathrm{~h}$ before the beginning of the experiment. In 15 tubules, the average absorption of a $2 \mathrm{mM}$ solution of $L-\left[{ }^{3} \mathrm{H}\right]$ proline was $75.9 \% \pm 2.3$, a value similar to that obtained in normal rats. When an excess of glycine, L-proline, or L-hydroxyproline was added, the same

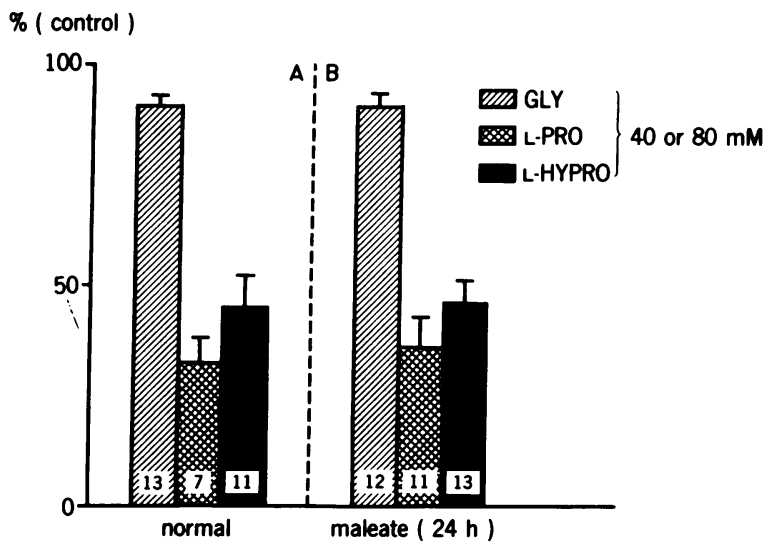

FIGURE 2 Microinjection of $2 \mathrm{mM} \mathrm{L}-\left[{ }^{2} \mathrm{H}\right]$ proline in normal (panel A) and maleate-treated rats (Panel B). Results are expressed as a percent of the control injection $(\mathrm{NaCl}$ $0.9 \%$ ). Figures at the base of each column represent the number of injected tubules.

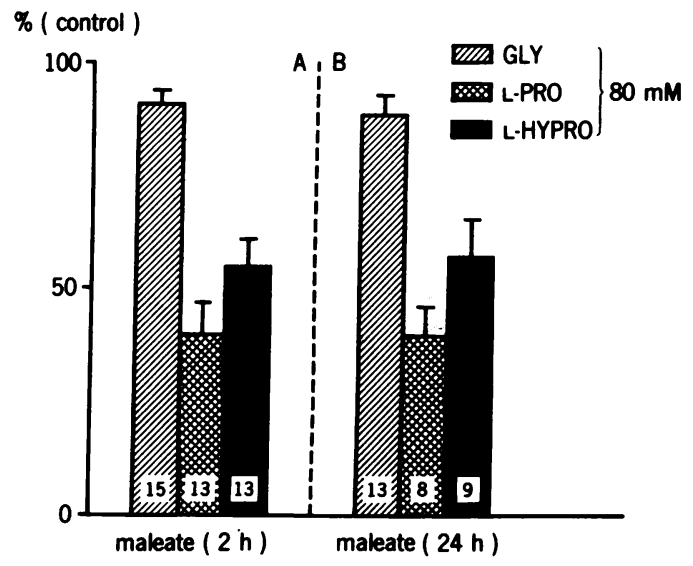

FIgURE 3 Microinjections of $0.2 \mathrm{mM}$ L- $\left[{ }^{3} \mathrm{H}\right]$ proline in treated rats having received an intraperitoneal injection of sodium maleate $2 \mathrm{~h}$ (panel A) or $24 \mathrm{~h}$ (panel B) previously.

type of competition was obtained between these molecules of related structure (Fig. 2, compare B and A).

A series of microinjections of $\mathrm{L}-\left[{ }^{3} \mathrm{H}\right]$ proline at a smaller concentration $(0.2 \mathrm{mM})$ was made in different rats $2 \mathrm{~h}$ after an intraperitoneal injection of sodium maleate (Fig. 3A). All treated animals showed the urinary abnormalities of the Fanconi syndrome, yet competition between imino acids and glycine was identical to that observed in normal rats. In presence of an excess of glycine, the absorption of $\mathrm{L}-\left[{ }^{3} \mathrm{H}\right]$ proline decreased by $10.1 \%$, while in presence of an identical concentration of L-proline, the absorption of $\mathrm{L}-\left[{ }^{3} \mathrm{H}\right]-$ proline was $39 \% \pm 6.8$ of the control; in presence of L-hydroxyproline, the decrease in absorption was diminished, being at $55.4 \% \pm 6.1$ of the control. Identical results were obtained $24 \mathrm{~h}$ after the maleate injection (Fig. 3B).

When microinjections into early and late proximal convolutions were compared, no qualitative differences were observed; the expected quantitative differences were noted. All these injections were made in the superficial convolutions accessible to micropuncture.

In a different series of microinjections, sodium maleate was added in the micropipette to rule out any direct competitive effect of maleate in situ. As seen in Fig. 4 , results were essentially identical to normal: the presence of maleate at the apical site of the tubular cells seemed not to interfere with either the absorption or the degree of inhibition introduced by an excess of unlabeled glycine, L-hydroxyproline, or L-proline.

A statistical analysis of the data obtained in Figs. 2, 3 , and 4 was made with the Student $t$ test: variations between normal and maleate-treated rats were not significant.

Stop-flow studies. In this series, comprising 31 experiments, the following molecules were used: $L-\left[{ }^{14} \mathrm{C}\right]-$ 


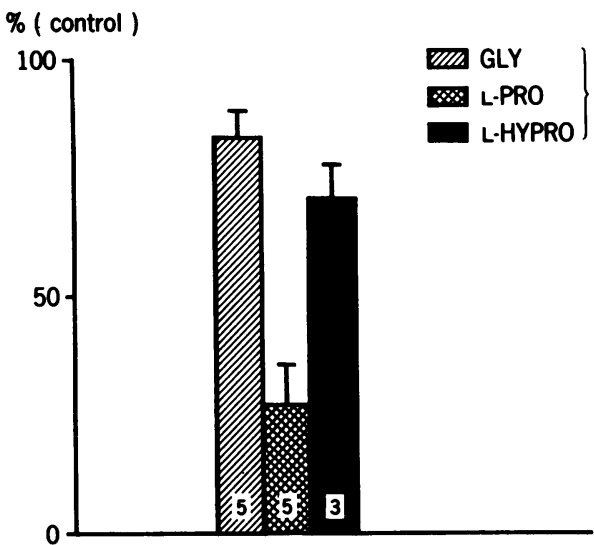

Figure 4 Microinjection of $\mathrm{L}-\left[{ }^{3} \mathrm{H}\right]$ proline $(0.2 \mathrm{mM})$ and sodium maleate $(3 \mathrm{mM})$ in normal rats. There is no competition between maleate and the imino acids at the apical site of the tubular cell.

lysine $+\left[{ }^{3} \mathrm{H}\right]$ Inulin $;\left[{ }^{14} \mathrm{C}\right]$ glycine $+\left[{ }^{3} \mathrm{H}\right]$ Inulin ; L- $\left[{ }^{55} \mathrm{~S}\right]-$ cystine $+\left[{ }^{3} \mathrm{H}\right]$ Inulin; $\left[{ }^{39} \mathrm{P}\right]$ phosphate $+\left[{ }^{3} \mathrm{H}\right]$ Inulin. In a few instances the isotopes were reversed; thus instead of tritiated inulin, $\left[{ }^{14} \mathrm{C}\right]$ inulin was used as a tracer for new filtrate to rule out any systematic error from radiolysis. Radiolysis is not unusual with tritiated compounds and gives rise to tritiated water, a highly diffusible molecule that could be the source of erroneous precession.

Figs. 5, 6, and 7 show the outflow pattern of $\left[{ }^{8} \mathrm{H}\right]-$ inulin and of $\mathrm{L}-\left[{ }^{14} \mathrm{C}\right]$ lysine or $\mathrm{L}-\left[{ }^{35} \mathrm{~S}\right]$ cystine or $\left[{ }^{14} \mathrm{C}\right]-$ glycine, following a pulse injection into the jugular vein. An identical excretion pattern was observed in all normal rats: inulin and the amino acid appeared si-
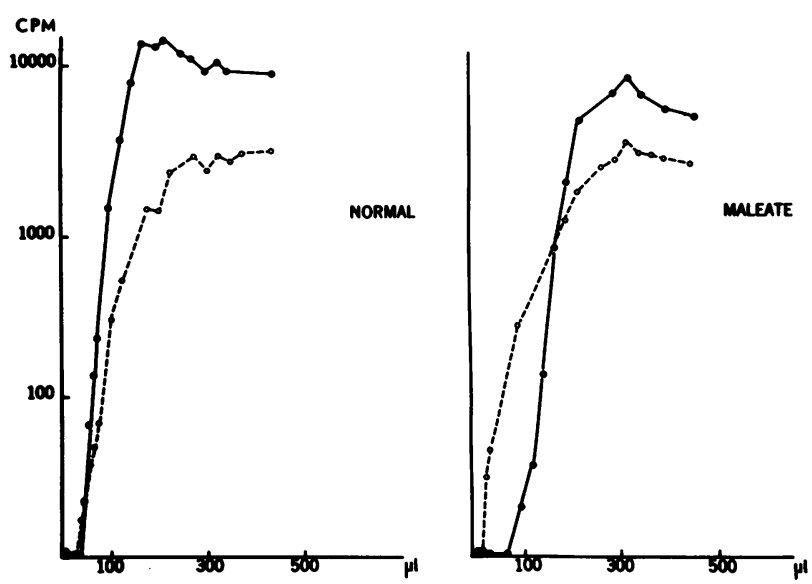

FIGURE 5 Stop-flow analysis of renal excretion of $\mathrm{L}-\left[{ }^{14} \mathrm{C}\right]-$ lysine $(\mathrm{O}---\mathrm{O})$ and $\left[{ }^{3} \mathrm{H}\right]$ inulin $(\bullet-0)$ in a rat undergoing mannitol diuresis. All maleate-treated rats showed a similar precedence of excretion of lysine over inulin, which favors a distal "secretion". Results are expressed on a semi-log scale.
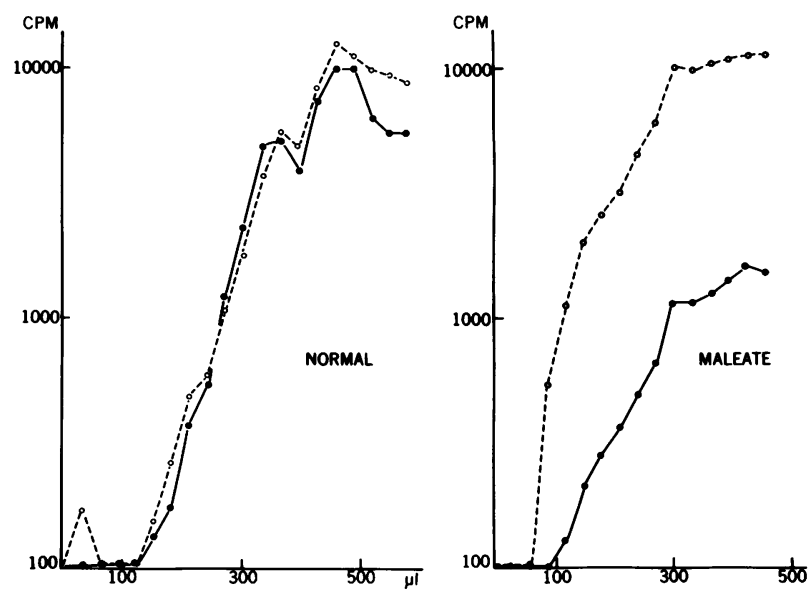

FIgURE 6 Stop-flow analysis of renal excretion of L- $\left[{ }^{\circ 5} \mathrm{~S}\right]-$ cystine $\left(\mathrm{O}_{--}-\mathrm{O}\right)$ and $\left[{ }^{3} \mathrm{H}\right]$ inulin $(-\bullet)$ in a rat undergoing mannitol diuresis. Results are expressed on a semi-log scale, which somewhat exaggerates the small peak seen in the first $100 \mu 1$. This peak was not seen in all animals, and could represent a secretion that has been suggested but never demonstrated decisively.

multaneously in the urine. A small precession peak of L-cystine was noted in some animals (Fig. 6), suggesting a slight "secretion" at the distal sites, as previously noted (14-17).

A more evident precession peak was noted in the experiments made with $\left[{ }^{82} \mathrm{P}\right]$ phosphate (Fig. 8). This peak was seen in most animals, even if not as evident as in other species such as the rabbit $(13,18)$.

In the series of animals treated with maleate, the amino acid or phosphate peak always preceded that of
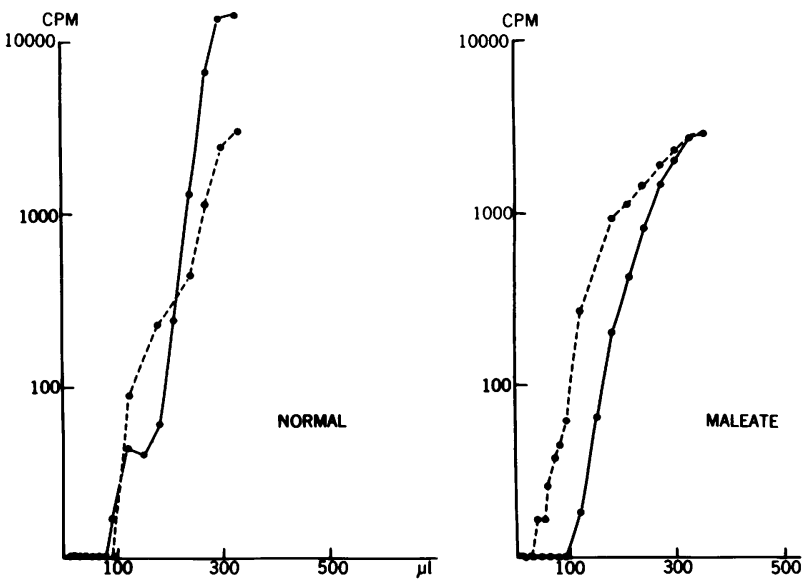

FIGURE 7 Stop-flow analysis of renal excretion of ${ }^{\left[{ }^{14} \mathrm{C}\right]-}$ glycine (๑- - $)$ and $\left[{ }^{3} \mathrm{H}\right]$ inulin $(\bullet-\bullet)$. All maleatetreated rats showed glycine preceding over inulin while in all normal animals, glycine and inulin were excreted at the same time. Note that the results are expressed in a semilog scale that exaggerates the samples with low activity. 

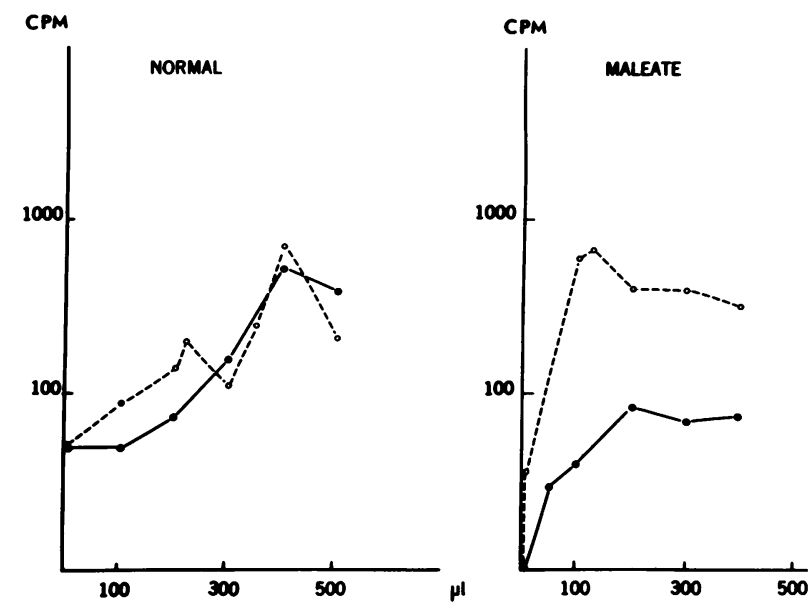

FIGURE 8 Stop-flow analysis of renal excretion of [ $\left.{ }^{20} \mathrm{P}\right]-$ phosphate $(\mathrm{O}--\mathrm{O})$ and $\left[{ }^{3} \mathrm{H}\right]$ inulin $(\bullet-\bullet)$. In normal rats, a small "secretion" peak was seen in a few instances. Note the marked precedence of phosphate in maleate-treated rats.

inulin. This precession peak was seen with all of the various labels studied. As the inulin curve represents the entry of a new glomerular filtrate, the presence of amino acids or phosphate in the first collection samples corresponds to an increased permeability of the cells of the nephron at its distal site.

Stop-flow microperfusion of single tubules. Only experiments in which labeled inulin was absent in the urine were considered in this series, based on 22 animals.

All normal animals showed a similar excretion pattern of the labeled glucose or amino aicd in the right and the left kidneys, as seen by the cumulated urinary excretion curve of Figs. 9 and 10. The mean ratio obtained from the left vs. the right cumulative excretion curves of each experiment was not significantly different from 1 (mean $\pm \mathrm{SEM}=0.98 \pm 0.08, n=13$ ).

In maleate-treated rats, an important portion of the injected molecules appeared in the right side, demonstrating the persistence of absorption in the proximal tubule of the perfused nephron (left). However, the excretion of labeled glucose or amino acid in the left kidney preceded that of the right kidney. This excreted portion was always greater in the perfused than in the unperfused side. The mean ratio of the left vs. the right cumulated excretion was found to be $2.68 \pm 0.59(n=9)$. This difference between normal and maleate-treated rats was highly significant $(P<0.001)$.

This phenomenon can be interpreted by increased antiluminal movements of the labeled molecules, readily absorbed from the proximal nephron, towards the apical side of adjacent distal tubules; once in the lumen of the distal nephron, these molecules are directly eliminated in the urine.

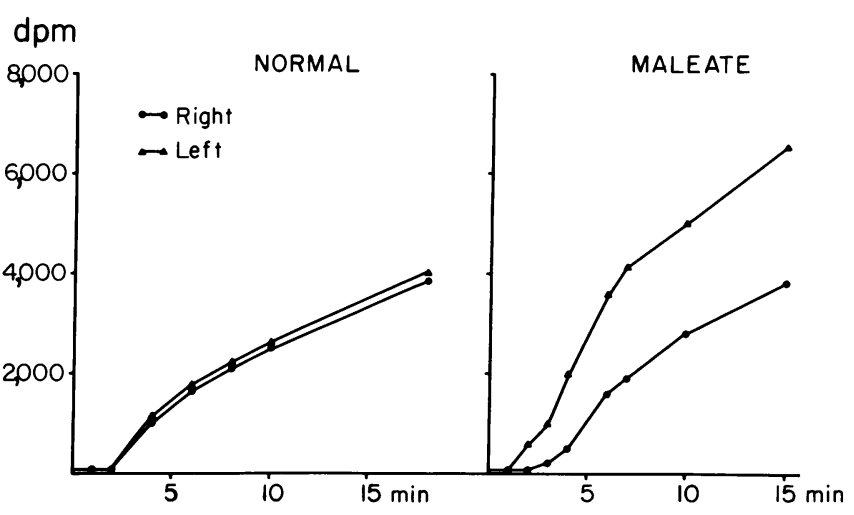

Figure 9 Stop-flow microperfusion of a single nephron into which was injected a solution of $\mathrm{L}-\left[{ }^{3} \mathrm{H}\right]$ valine and $\left[{ }^{14} \mathrm{C}\right]$ inulin. Inulin excretion is not represented since it was not recovered in the urine. The excretion curve of the two kidneys was identical in normal rats. In maleate-treated rats, there was still some excretion in the control (right) kidney, indicating that absorption still takes place from the luminal site of the experimental kidney. Note that in the left kidney, L-valine is excreted in a greater amount and precedes the excretion of the right kidney.

\section{DISCUSSION}

The microinjection technique has the advantage of an in vivo approach in which tubular and vascular compartments as well as cell orientation are preserved. This technique allows direct access to both the vascular and tubular poles in such a manner that the functions of the luminal and basal membranes can be differentiated. In the microinjection technique, both the total amount and the radioactivity of amino acid injected are known exactly but only the radioactivity excreted is measured. Total amino acid reabsorption may be deduced from

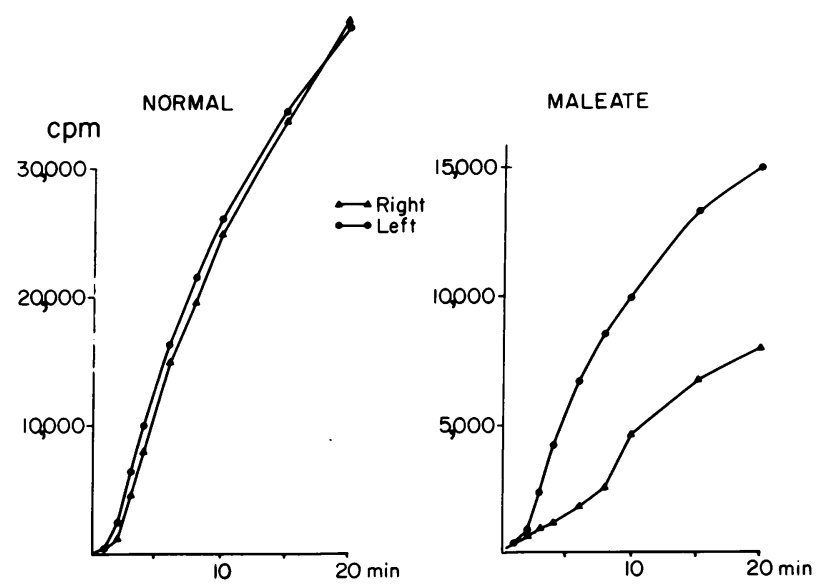

FIGURE 10 Stop-flow microperfusion of a single nephron into which was injected a solution of $3-O-$ methyl-D- $\left[{ }^{3} \mathrm{H}\right]$ glucose and $\left[{ }^{14} \mathrm{C}\right]$ inulin. See Fig. 9 for further explanation. 
radioactivity reabsorption only if no change in specific activity occurs during the intratubular transit. The validity of this assumption was discussed in previous papers $(9,10)$. Our data suggested that bidirectional exchanges of amino acids are not very important in vivo and that they do not modify significantly the calculation of excretion and reabsorption of amino acids. However, antiluminal movements of amino acids do exist in vivo and tubular cells of the renal cortex are permeable to these molecules from both surfaces.

It is generally thought that amino acids are actively transported by "carrier proteins" located at the brush border of proximal tubules. A defect in proximal tubule reabsorption of amino acids, glucose, phosphate, and other molecules was originally suggested by Fanconi when he described this syndrome (1). This complex syndrome is also referred to as the Lignac-de ToniDebré-Fanconi syndrome and can be not only hereditary but also acquired by extrinsic poisons such as heavy metals, outdated tetracyclines, and maleic acid. In these latter conditions, a destruction of the transport mole- cules could explain the deficient tubular absorption; such a destruction would be reflected by the absence of competition between molecules of related structures. Our results show that the transport system common to the iminoglycine group in the normal rat is intact in maleate-treated rats. Indeed, the data obtained in these series show reabsorption and competition characteristics identical to those obtained in normal rats (compare Figs. 2 and 3 to Fig. 1). The persistence of absorption and competition at the luminal membrane indicates the integrity of transport reactive sites and, consequently, a normal influx. A similar conclusion can be reached for sugars from the stop-flow analysis of Figs. 9 and 10.

Similarly, at the binding sites, no directly competitive effect, analogous to that of phlorizin and glucose, seems to be involved between maleate and amino acids to explain the absorption defect. The absence of an effect of maleate at the luminal membrane is analogous to those reported by Silbernagl and Deetjen (19), or Chan and Huang (20), and Györy and Kinne (21): these authors could detect no inhibitory effect when 2,4-dinitrophenol,

\section{NEPHRON}
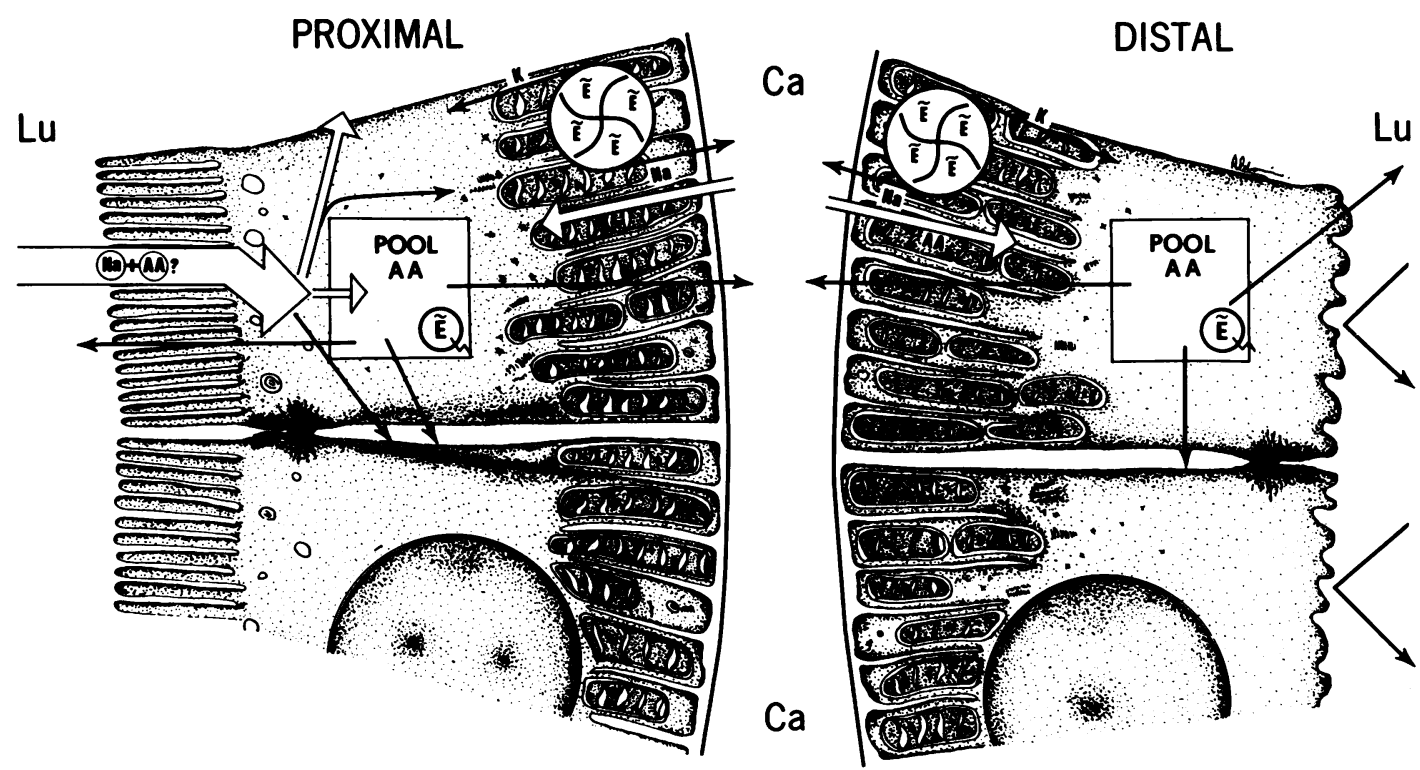

FIGURE 11 A schematic representation of the movements of amino acids in the normal nephron. At the proximal tubule, amino acids gain access to the cell through the microvillosities of the apex or through the infoldings of the antiluminal membrane. Since there is an intracellular accumulation of amino acids against a concentration gradient, active transport has to be postulated; however, at the brush border, a carrier-mediated process might be facilitated by the sodium gradient as suggested by various authors. Efflux will take place at all membranes. At the distal tubule, similar amino acid movements (efflux and influx) are seen except that there is no entry of amino acids from the lumen (9). Lu, lumen; Ca, capillary; AA, amino acids; E, energy. 


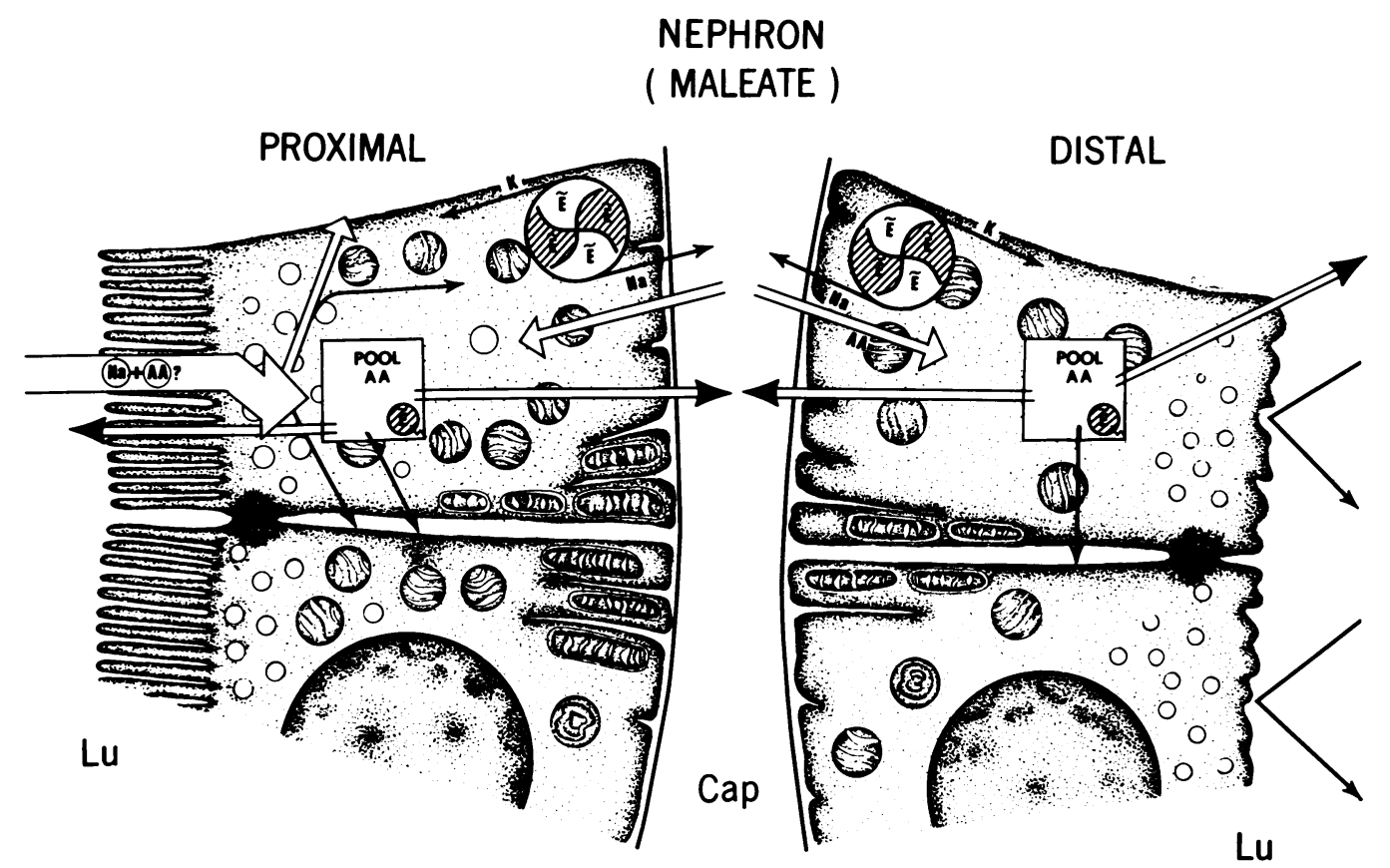

FIGURE 12 In the maleic acid model, the cell structure is modified by intense vacuolization, globular and swollen mitochondria, and loss of the infoldings of the basal membrane. Intracellular accumulation of amino acid is decreased despite a rather normal entry at the luminal side. The efflux of amino acids is increased. This efflux can be partially or totally corrected in the proximal nephron since the reabsorption capacity of these cells is very high (9). At the distal sites, the efflux of molecules cannot be corrected, which will lead to their subsequent excretion. This schematic view is based on data of various authors (7-9, 23-30). Abbreviations as in Fig. 11.

oligomycin, antimycin $\mathrm{A}$, or cyanide was perfused directly into the renal tubules.

It can be concluded from our results that the experimental aminoaciduria of the maleic acid model is not secondary to a defective absorption of the molecules at the luminal membrane. A similar conclusion has been reached about the antiluminal membrane both in vitro (7) and in vivo (8). By analyzing the transport of $\alpha$-amino-isobutyric acid in kidney cortex slices with a digital computer, Rosenberg and Segal (7) found that maleate action could not be explained by a diminution of influx. A modification in the permeability of the basement membrane, as suggested by Worthen (22), is also excluded by microinjections made into peritubular capillaries (8).

The demonstration of a normal influx at the luminal membrane in pretreated rats and the similarity of the maleate effect to the effects of metabolic inhibitors suggest that maleate could modify energetic processes. Maleate could indeed cause a diminution or a complete block of a common energy source at the Krebs cycle level, as suggested by Angielski and Rogulski (23), Worthen (22), and Schubert and Barritt (24). This hypothesis is also supported by in vitro (7) and in vivo $(25,26)$ data showing that maleate decreases the accumulation of intracellular amino acids. Ultrastructure studies confirm that maleate may cause mitochondrial changes (22, 27-29). That maleate diminishes the ATP production of mitochondria does not preclude its action at other levels. In fact, the inhibition of the transport enzyme Na-K-ATPase (30) suggests the occurrence of a defective ATP synthesis. In our study, major membranous changes were seen at the base of the cell where the $\mathrm{Na}-\mathrm{K}-\mathrm{ATPase}$ involved in active transport is localized (31-34). While the brush border structure of the proximal nephron appeared to be well preserved $(28,29)$, a major modification of the relationship between mitochondria and the network of perimitochondrial membranes of the proximal and distal nephron was noted. These membranes disappear within $24 \mathrm{~h}$ after the injection of maleate. From 72 to $96 \mathrm{~h}$ after maleate injection, cell structure is shown to have reverted to normal, while at the same time biochemical abnormalities in the urine are no longer detectable. This suggests that maleate affects transport mechanisms at membranous level and is in accordance with the conclusion of Obaid, et al. 
(35), who showed that maleic anhydride reacts rapidly and specifically with amino groups associated with the protein fraction of the red cell membrane. These authors demonstrated changes in membrane permeability characteristics with maleate. Such membrane permeability modifications could explain the efflux acceleration noted in vitro in cortex slices (7) and in vivo with microinjection into the peritubular capillaries (8). The increased glucose concentration measured in the proximal tubule of maleate-treated rats can also be interpreted by an increased back-flux (36). Some of the data (such as the modifications of serum $\mathrm{Na}$ and $\mathrm{K}$ ) obtained by Kramer and Gonick (37) could also be interpreted by an increased membrane permeability. It is difficult to explain the kaliuresis by an increased distal tubular secretion, an energy-linked transport process, if maleate is a "potent inhibitor of the ATP-Na-K-ATPase system."

Our studies indicate that, contrary to the generally accepted explanation of the Fanconi syndrome $(5,6$, 37 ), maleate action is not confined to the proximal tubule. Maleate modifies the ultrastructure of both the proximal and the distal nephron.

The efflux phenomena, noted previously $(7,8)$ and in this study, occur most likely at both distal and proximal nephrons. However, since there is a rather normal entry of molecules in the proximal tubule, this efflux can be partially or totally corrected downstream. At the distal nephron, this is not the case: there is no absorption of amino acids (9) and absorption of phosphate is rather small $(38,39)$ or nonexistent $(40,41)$; therefore, the molecules that exit at this site are excreted directly into the urine. This explains the modification in the urinary outflow pattern seen in our stop-flow experiments (Figs. 5-8) : that the curve of the amino acids precedes that of inulin reflects a leak at the distal sites, as generally accepted $(12,13,42)$. The presence of high glucose concentrations at distal sites in maleatetreated rats (36) is also in favor of this hypothesis.

In conclusion, Fig. 11 is a schematic representation of the movement of amino acids in the normal nephron. This model does not take into account the variation of cell characteristics along the nephron (43-45). In the maleic acid model, depicted in Fig. 12, there seems to be a normal entry of amino acids into the proximal nephron; the increased efflux at the luminal membrane can be partially or totally corrected farther away in the nephron, since the reabsorption capacity of the cell is very high. In fact, all amino acids can be normally reabsorbed in the 1 st $\mathrm{mm}$ past the glomerulus (9), which agrees with the electrophysiological data of Kokko (45). At the distal site, the efflux of molecules cannot be corrected. Our results suggest that the phosphaturia, aminoaciduria, and glycosuria of the experimental Fan- coni syndrome can be explained by a modification of the cell membrane permeability (increased efflux) at distal sites of the nephron, rather than by a modification of the membrane transport (decreased influx) at the proximal sites, as is currently accepted. They also stress the importance of efflux phenomena in membrane transport.

\section{ACKNOWLEDGMENTS}

The authors wish to thank Mrs. Louise Alle-Ando, Misses Christiane Sabourin, Claudette Doyon, and Christiane Laurier, Messrs. Edouard Rupnik, and Robert Peloquin for skillful assistance, and Miss June Manson for reviewing the manuscript.

This work was supported by grant MT-2862 of the Medical Research Council of Canada.

\section{REFERENCES}

1. Fanconi, G. 1936. Der frühenfantile nephrotisch-glykosurische Zwergwuchs mit hypophostämischer Rachitis. Jahrb. Kinderheilkd. 147: 299-338.

2. Scriver, C. R., and L. E. Rosenberg. 1973. Amino acid metabolism and its disorders. W. B. Saunders Company, Philadelphia, Pa. 491 pp.

3. Clay, R. D., E. M. Darmady, and M. Hawkins. 1953. The nature of the renal lesion in the Fanconi syndrome. J. Pathol. Bacteriol. 65: 551-558.

4. Darmady, E. M., and F. Stranack. 1957. Microdissection of the nephron in disease. Br. Med. Bull. 13: 21-26.

5. Berliner, R. W., T. J. Kennedy, and J. G. Hilton. 1950. Effect of maleic acid on renal function. Proc. Soc. Exp. Biol. Med. 75 : 791-794.

6. Harrison, H. E., and H. C. Harrison. 1954. Experimental production of renal glycosuria, phosphaturia, and aminoaciduria by injection of maleic acid. Science (Wash. D. C.). 120: 606-608.

7. Rosenberg, L. E., and S. Segal. 1964. Maleic acid-induced inhibition of amino acid transport in rat kidney. Biochem. J. 92 : 345-352.

8. Bergeron, M., and M. Vadeboncoeur. 1971. Microinjections of L-leucine into tubules and peritubular capillaries of the rat. II. The maleic acid model. Nephron. 8: 367374.

9. Bergeron, M., and F. Morel. 1969. Amino acid transport in rat renal tubules. Am. J. Physiol. 216: 11391149.

10. Dubord, L., and M. Bergeron. 1974. Multiplicité des systèmes transporteurs à la membrane luminale du néphron chez le rat normal. Rev. Can. Biol. 33: 99-109.

11. Gottschalk, C. W., and M. Mylle. 1956. Micropuncture study of pressures in proximal tubules and peritubular capillaries of the rat kidney and their relation to ureteral and renal venous pressures. Am. J. Physiol. 185: 430439.

12. Malvin, R. L., W. S. Wilde, and L. P. Sullivan. 1958. Localization of nephron transport by stop flow analysis. Am. J. Physiol. 194: 135-142.

13. Lambert, P. P., F. Vanderveiken, J. P. De Koster, R. J. Kahn, and M. De Mytternaere. 1964. Study of phosphate excretion by the stop-flow technique. Effects of parathyroid hormone. Nephron. 1: 103-117.

14. Dent, C. E., B. Senior, and J. M. Walshe. 1954. The pathogenesis of cystinurea. II. Polarographic studies of the metabolism of sulphur-containing amino-acids. $J$. Clin. Invest. 33: 1216-1226. 
15. Arrow, V. K., and R. G. Westall. 1958. Amino acid clearances in cystinuria. J. Physiol. (Lond.). 142: 141146.

16. Frimpter, G. W. 1961. The disulfide of L-cysteine and L-homocysteine in urine of patients with cystinuria. $J$. Biol. Chem. 236: PC51-PC53.

17. Crawhall, J. C., E. F. Scowen, C. J. Thompson, and R. W. E. Watts. 1967. The renal clearance of amino acids in cystinuria. J. Clin. Invest. 46: 1162-1171.

18. Hausser, C., and M. Bergeron. 1974. Etude de la perméabilité du néphron distal aux phosphates chez le rat et le lapin. Union Méd. Can. 103: 635. (Abstr.).

19. Silbernagl, S., and P. Deetjen. 1971. Glycine reabsorption in rat proximal tubules. Microperfusion studies. Pflügers Arch. Eur. J. Physiol. 323 : 342-350.

20. Chan, Y-L., K. C. Huang. 1971. Microperfusion studies on renal tubular transport of tryptophane derivatives in rats. Am. J. Physiol. 221 : 575-579.

21. Györy, A. Z., and R. Kinne. 1971. Energy source for transepithelial sodium transport in rat renal proximal tubules. Pflügers Arch. Eur. J. Physiol. 327: 234-260.

22. Worthen, H. G. 1963. Renal toxicity to maleic acid in the rat. Enzymatic and morphologic observations. Lab. Invest. 12: 791-801.

23. Angielski, S., and J. Rogulski. 1962. Effect of maleic acid on the kidney. I. Oxidation of Krebs cycle intermediates by various tissues of maleate intoxicated rats. Acta Biochim. Pol. 9: 357-365.

24. Schubert, E. T., and A. S. Barritt. 1966. Oxidation of Krebs cycle intermediates by renal cortex in maleateinduced renal disease. Fed. Proc. $25: 237$. (Abstr.)

25. Bergeron, M. 1971. Renal amino acid accumulation in maleate-treated rats. Rev. Can. Biol. 30: 267-272.

26. Ausiello, D. A., S. Segal, and S. O. Thier. 1972. Cellular accumulation of L-lysine in rat kidney cortex in vivo. Am. J. Physiol. 222: 1473-1478.

27. Laporte, P., and M. Bergeron. 1972. Rôle des membranes périmitochondriales dans le transport actif au niveau du néphron. J. Microsc. (Paris). 14: 60a. (Abstr.)

28. Schärer, K., T. Yoshida, L. Voyer, S. Berlow, G. Pietra, and J. Metcoff. 1972. Impaired renal gluconeogenesis and energy metabolism in maleic acid-induced nephropathy in rats. Res. Exp. Med. 157: 136-152.

29. Bergeron, M., and P. Laporte. 1973. Effêt membranaire du maléate au niveau du néphron proximal et distal. Rev. Can. Biol. 32: 275-279.

30. Kramer, H. J., and H. C. Gonick. 1970. Experimental Fanconi syndrome. I. Effect of maleic acid on renal cortical Na-K-ATPase activity and ATP-levels. J. Lab. Clin. Med. 76: 799-808.

31. Spater, H. W., A. B. Novikoff, and B. Masek. 1958. Adenosine-triphosphatase activity in the cell membranes of kidney tubule cells. J. Biophys. Biochem. Cytol. 4: 765-770 + plates 388-391.
32. Ericsson, J. L. E., and B. F. Trump. 1969. Electron microscopy of the uriniferous tubules. In The Kidney. Morphology, Biochemistry, Physiology. C. Rouiller and A. F. Muller, editors. Academic Press, Inc., New York. $351-447$.

33. Heidrich, H-G., R. Kinne, E. Kinne-Saffran, and K. Hannig. 1972. The polarity of the proximal tubule cell in rat kidney. Different surface charges for the brushborder microvilli and plasma membranes from the basal infoldings. J. Cell Biol. 54 : 232-245.

34. Schmidt, U., and U. C. Dubach. 1971. Na-K stimulated adenosine triphosphatase: intracellular localisation within the proximal tubule of the rat nephron. Pfiugers Arch. Eur. J. Physiol. 330: 265-270.

35. Obaid, A. L., A. F. Rega, and P. J. Garrahan. 1972. The effects of maleic anhydride on the ionic permeability of red cells. J. Membrane Biol. 9: 385-401.

36. Wen, S. F. 1974. Significance of distal glucose transport in regulating glucose excretion. Clin. Res. 22: 550A. (Abstr.)

37. Kramer, H. J., and H. C. Gonick. 1973. Effect of maleic acid on sodium-linked tubular transport in experimental Fanconi syndrome. Nephron. 10: 306-319.

38. Amiel, C., H. Kuntziger, and G. Richet. 1970. Micropuncture study of handling a phosphate by proximal and distal nephron in normal and by parathyroidectomized rat. Evidence for distal reabsorption. Pfü̈gers Arch. Eur. J. Physiol. 317 : 93-109.

39. Le Grimellec, C., N. Roinel, and F. Morel. 1974. Simultaneous $\mathrm{Mg}, \mathrm{Ca}, \mathrm{P}, \mathrm{K}$, and $\mathrm{Cl}$ analysis in rat tubular fluid. IV. During acute phosphate plasma loading. Pflügers Arch. Eur. J. Physiol. 346: 189-204.

40. Staum, B. B., R. J. Hamburger, and M. Goldberg. 1972. Tracer microinjection study of renal tubular phosphate reabsorption in the rat. J. Clin. Invest. 51: 2271-2276.

41. Brunette, M. G., L. Taleb, and S. Carrière. 1973. Effect of parathyroide hormone on phosphate reabsorption along the nephron of the rat. Am. J. Physiol. 225: 10761081 .

42. Cooke, H., and J. A. Young. 1973. Amino acid transport in the developing chicken kidney. Aust. J. Exp. Biol. Med. Sci. 51: 199-207.

43. Lingard, J. M., G. Rumrich, and J. A. Young. 1972. Amino acid reabsorption in various sections of the proximal convolution of the rat nephron. Proc. Aust. Physiol. Pharmacol. Soc. 2: 106-107.

44. Boulpaep, E. L. 1971. Electrophysiological properties of the proximal tubule: importance of cellular and intracellular transport pathways. In Electrophysiology of epithelial cells. G. Giebisch, editor. Friedrich-Karl Schattauer-Verlag, Stuttgart, W. Germany. 91-112.

45. Kokko, J. P. 1973. Proximal tubule potential difference. Dependence on glucose, $\mathrm{HCO}_{3}$, and amino acids. J. Clin. Invest. 52: 1362-1367. 